\title{
PENGEMBANGAN MULTIMEDIA INTERAKTIF IPA DENGAN FITUR FEEDBACK UNTUK SISWA KELAS VIII
}

\author{
Muhamad Firdaus Alfiansyah, Eka Pramono Adi, Yerry Soepriyanto \\ Teknologi Pendidikan, Fakultas Ilmu Pendidikan, Universitas Negeri Malang. \\ Jl. Semarang No.5, Malang, 65145, Indonesia. \\ muh.firdaus.a@gmail.com
}

\section{Article History}

Received: 30 Januari 2021, Accepted: 28 Maret 2021, Published: 20 Februari 2022

\begin{abstract}
Abstrak
Penggunaan media pembelajaran buku paket maupun LKS membuat pebelajar cepat bosan sehingga malas mengikuti pembelajaran. Pembelajaran berbasis multimedia interaktif dengan fitur feedback dapat memberikan motivasi kepada peserta didik, mengaktifkan peserta didik dalam memberikan tanggapan, umpan balik serta mendorong melakukan praktik-praktik yang benar. Tujuan pengembangan ini adalah menghasilkan sebuah produk multimedia interaktif dengan fitur feedback IPA msteri sistem peredaran darah. Produk berupa aplikasi yang dapat meningkatkan motivasi belajar dan ketertarikan pebelajar selama proses pembelajaran serta membuat pebelajar lebih mudah memahami materi peredaran darah manusia. Model penelitian dan pengembangan yang digunakan adalah model yang dikemukakan Lee dan Owens. Secara keseluruhan hasil tanggapan ahli media, ahli materi, guru mata pelajaran dan pebelajar dinyatakan layak maka dapat disimpulkan multimedia interaktif dengan fitur feedback IPA materi sistem peredaran darah manusia kelas VIII telah memenuhi kriteria layak digunakan dalam kegiatan pembelajaran.
\end{abstract}

Kata kunci: Multimedia Interaktif; Feedback; IPA; Sistem Peredaran Darah Manusia

\begin{abstract}
The use of package book and student worksheet learning media made student bored quickly therefore they are lazy to follow the learning. The interactive media based learning with feedback feature can give motivation to the student, activating students in giving responses, feedback and encourage to do the right practices. The purpose of this development is to produce an interactive multimedia product with feedback feature natural science circulatory system material. The product is an application that can increase the motivation to learn and students' interest during the learning process and make student easier to understand the human circulatory material. The research and development model used is the model by Lee and Owens. The result of media expert's material, subject teachers and students is worth using, therefore it can be concluded that the interactive multimedia with feedback feature natural science human circulatory system material VIII grade has fulfilled the eligible criteria to be used in the learning activity.
\end{abstract}

Keyword: Interactive Multimedia, Feedback, Natural Science, Human Circulatory System 


\section{PENDAHULUAN}

Pendidikan yakni sebuah kegiatan yang dilaksanakan secara sadar oleh pengajar dan pebelajar, yang mempunyai maksud untuk meningkatkan pengetahuan serta dapat membuka wawasan lebih luas serta dapat menambah wawasan secara luas. Menurut Sadiman dkk (2014) proses belajar dapat berlangsung karena terciptanya interaksi individu dengan sumber belajarnya, sumber belajar itu bias dari mana saja sumbernya. "Penggunaan komputer memungkinkan berlangsungnya proses pembelajaran secara individual dengan meningkatkan kemandirian dalam prosesnya sehingga pebelajar akan mendapat proses yang jauh lebih bermakna dibandingkan dengan pembelajaran konvensional" Rusman (2012).

Penggunaan buku paket maupun LKS semakin lama menjadikan pebelajar merasa bosan sehingga malas mengikuti pembelajaran. Pembelajaran berbasis multimedia interktif dengan fitur feedback dapat menjadikan pebelajar lebih termotivasi, juga membuat pebelajar lebih aktif menyampaikan tanggapan, balikan, dan membuat pebalajar dapat menjalankan praktik-praktik yang benar. Melalui multimedia ini pebelajar dapat mengetahui kesalahan dan kekurangannya sehingga dapat memperbaiki baik secara perorangan dengan bantuan pengajar.

Media pembelajaran merupakan salah satu implementasi kemajuan teknologi informasi dan Komunikasi (Praherdhiono \& Adi, 2008) Perangkat komputer sebagai salah satu perangkat pembelajaran kekinian dengan berbagai variasi. Salah satu variasi manfaat komputer adalah sebagai media pembelajaran dalam proses belajar mengajar. Arsyad (2011) menyatakan bahwa media menjadi salah satu komponen yang penting yang menjadi alat dalam memusatkan perhatian siswa yang mampu dimanfaatkan untuk menyajikan materi dalam kegiatan belajar dan mengajar. Dengan demikian media mesti di design sedemikian rupa dengan tujuan untuk memberi kemudahan siswa dalam kegiatan pembelajaran sebagai alat perantara dalam menyampaikan materi. Hamalik (2011) penggunaan media pembelajaran mampu memberikan pengaruh secara psikologis kepada siswa bahkan mampu membangkitkan keinginan yang baru sehingga siswa bisa lebih senang dalam mengikuti pelajaran. Media Pendidikan sebagai salah satu sumber belajar yang dapat menyalurkan pesan dapat. Sadiman (2010) mengungkapkan perbedaan gaya belajar, minat, bakat, letak geografis, biaya, jarak, waktu, dan lain -lain dapat diatasi dengan pemanfaatan media pendidikan.

Multimedia Interaktif dalam Pembelajaran menurut Hofsteder dalam Darmawan (2015) Multimedia merupakan gabungan dari teks, grafik, audio gambar bergerak (video dan animasi) yang memungkinkan pemakai untuk melakukan navigasi, berinteraksi, berkreasi dan berkomunikasi. Multimedia interaktif termasuk salah satu media pembelajaran yang dapat digunakan dalam proses pembelajaran. Di dalam proses pemebelajaran multimedia interaktif bertindak sebagai penghubung antara pengejar dan pebelajar. Pembelajaran menggunakan multimedia interaktif tidak akan menjadikan siswa bosan, karena multimedia interaktif memiliki komponen seperti teks, gambar, suara, video dan animasi yang menarik bagi pebelajar. Dengan perpaduan dari beberapa komponen di dalam multimedia interaktif diharapkan dapat memotivasi pebelajar untuk aktif dalam mengikuti pembelajaran di kelas. Hal ini sesuai dengan yang disampaikan oleh Richard (2005) yaitu belajar melalui multimedia menjadikan siswa aktif dalam pembelajaran, siswa dapat memperoleh situasi yang menyenangkan dan menghilangkan rasa bosan dalam pemebalajaran. Meskipun penggunaan multimedia interaktif dalam pembelajaran tidak dapat menggantikan kedudukan dan peran pengajar seratus persen, namun setidaknya dengan kehadiran multimedia interaktif dalam pembelajaran dapat mengatasi rasa bosan pada diri siswa akibat pembelajaran yang bersifat konvensional.

Menurut Eggen \& Kauchak (1994) Umpan balik adalah informasi yang diberikan pengajar kepada pebelajar tentang tingkah laku tertentu dengan tujuan untuk meningkatkan performa 
(kinerja) pebelajar. Balikan juga dapat digunakan sebagai alat ukur sejauh mana pembelajaran yang telah dicapai oleh pebelajar untuk bisa melihat sebarapa besar pemahaman tentang materi tersebut.

Dengan multimedia diharapkan menaikkan keinginan belajar pebelajar dalam IPA pokok bahasan peredaran darah manusia melalui mengpenggunaan multimedia berjenis interaktif fitur feedback dan melalui fitur feedback ini pebelajar dapat melihat seberapa besar pemahaman tentang materi yang dipelajari. Penggunaan multimedia berjenis interaktif dengan fitur feedback pada aktivitas pembelajaran menjadikan aktivitas pembelajaran menjadi berbeda karena menggunakan teknologi komputer sehingga mampu memikat perhatian pebelajar untuk mempelajari pokok bahasan tersebut.

Hasil penelitian sebelumnya telah dibuktikan Oman et al., (2020) penggunaan video feedback dalam pembelajaran futsal secara signifikan efektif meningkatkan motivasi. Melalui VFB, visualisasi informasi gerakan yang dilakukan pada saat proses pembelajaran secara langsung dapat membantu peserta didik dalam meregulasi umpan balik (feedback) untuk dapat memperbaiki, mempertahankan, atau meningkatkan gerakan tersebut. Hasil penelitian dari Pandu et al., (2018) terdapat perbedaan motivasi dan hasil belajar yang cukup signifikan antara pebelajar yang diajarkan dengan pemberian balikan dan pebelajar yang diajar tanpa pemberian balikan. Penelitian yang dilakukan oleh (Yunarni \& Nova, 2020) pembelajaran dengan pemberian feedback dapat meningkatkann motivasi belajar siswa kelas 2 SDN 3 Pandak.

Permasalahan penelitian ini yakni kurangnya motivasi belajar dan ketertarikan pebelajar jika hanya menggunakan LKS dan buku paket pada saat mata pelajaran IPA berlangsung. Perihal tersebut dapat dikembangkan melalui multimedia berjenis interaktif dengan fitur feedback. Selain untuk memudahkan pemahaman materi, dengan feedback pengajar dapat mengukur seberapa besar ketrampilan pebelajar dalam mencerna materi.

Tujuan pengembangan ini yakni menciptakan sebuah produk multimedia berjenis interaktif dengan fitur feedback IPA pokok bahasan peredaran darah. Produk berupa aplikasi yang bisa menambah motivasi belajar dan ketertarikan pebelajar selama pembelajaran menjadikan pebelajar lebih gampang memahami pokok bahasan peredaran darah manusia setelah menjalankan multimedia berjenis interaktif dengan fitur feedback.

Berdasarkan masalah-masalah yang sudah dipaparkan maka perlu adanya media pembelajaran yang mampu menunjang pembelajaran untuk menarik perhatian pebelajar serta mampu memotivasi pebelajar dalam belajar. Yaitu menggunakan multimedia interaktif dengan fitur feedback. Pembelajaran IPA kelas VIII memuat pokok bahasan sistem peredaran darah manusia perlu menggunakan media yang bisa memotivasi serta meningkatkan minat belajar pebelajar. Multimedia ini merupakan salah satu alternatif media yang dapat memenuhi kebutuhan pada saat pembelajaran.

\section{METODE}

Produk yang diciptakan dalam penelitian ini yakni aplikasi multimedia berjenis interaktif dengan fitur feedback dengan pokok bahasan Sistem Peredaran Darah Manusia untuk SMP kelas VIII. aplikasi ini dibuat melalui Lectora Inspire. Model penelitian dan pengembangan penelitian ini menggunakan model penelitian pengembangan yang dikemukakan Lee dan Owens (2004). Model ini dipilih karena khusus mengembangkan multimedia. Model pengembangan ini dikatakan sebagai model prosedural karena urutan prosesnya tersusun secara sistematis dan setiap langkah pengembangan mempunyai langkah pengembangan yang tersusun jelas.

Adapun prosedur penelitian dan pengembangan yang dipakai dalam multimedia berjenis interaktif melalui fitur feedback yakni: Tahap awal yakni penilaian dan analisis yang dipisahkan menjadi dua bagian yaitu penilaian kebutuhan serta analisis awal akhir. Tahap kedua yakni desain 
(design) merupakan tahap perencanaan produk/media yang ingin dikembangkan. Tahap ketiga adalah tahap Pengembangan dan Implementasi, nantinya dilakukan validasi ahli media dan validasi ahli materi terhadap hasil pengembangan. Dalam uji coba produk ini ada lima tahapan yaitu (1) desain uji coba, (2) subjek uji coba, (3) jenis data, (4) instrument pengumpulan data, (5) teknik analisis dan interpretasi data.

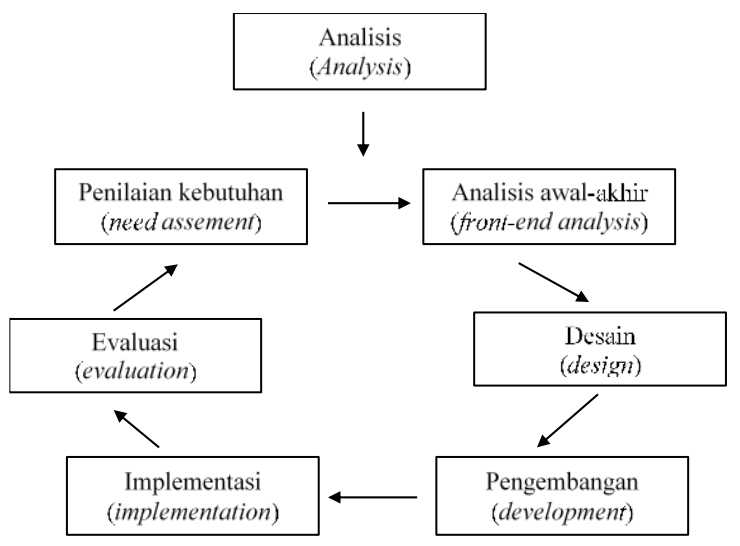

Gambar 1. Model Pengembangan Lee \& Owens (2004)

Subjek uji coba dalam pengembangan ini adalah dosen jurusan Teknologi Pendidikan sebagai ahli media, pengajar IPA SMPN 1 Pagelaran sebagai ahli materi dan sebagai pengajar mata pelajaran, dan pebelajar kelas VIII SMPN 1 Pagelaran sebagai audiens. Jenis data yang dipakai penelitian pengembangan ini menggunakan data kualitatif dan kuantitatif. Data kualitatif berasal dari saran-saran perbaikan melalui angket validasi yang diisi oleh ahli media, ahli materi dan angket yang telah diisi oleh pebelajar kelas VIII SMPN 1 Pagelaran setelah melakukan pembelajaran memakai multimedia berjenis interaktif dengan fitur feedback. Data kuantitatif sendiri didapat dari angket yang diisi oleh ahli media, ahli materi, dan audiens/pebelajar.

Instrumen pengumpulan data yang dipakai pada penelitian ini menggunakan pendekatan kuantitatif berupa angket, jenis angket yang dipakai merupakan jenis angket tertutup, yaitu jawaban telah tersedia sehingga responden memilih jawaban yang dianggap benar sesuai dengan jawaban yang sudah tersedia. Teknik analisis data dan evaluasi para ahli untuk uji coba produk adalah berupa data kualitatif dan data kuantitatif dalam bentuk presentase. Data kuantitatif didapat dari ahli media dan juga ahli materi yang berupa angket kuisioner, data skoring dari format evaluasi ahli media dan ahli materi yang dipakai untuk mengukur presentase hasil pengumpulan data pengembangan awal. Data kualitatif didapat dari tanggapan serta saran-saran dari ahli media dan ahli materi yang digunakan untuk bahan dalam melakukan revisi produk media yang dikembangkan.

\section{Tabel 1. Kisi-kisi Instrumen Responden}

\begin{tabular}{|c|c|c|c|c|}
\hline No. & Aspek & Indikator & Butir & Jumlah Butir \\
\hline \multirow[t]{2}{*}{1.} & \multirow[t]{2}{*}{ Kemudahan Pemahaman } & Mempermudah pemahaman materi. & 1 & \multirow{2}{*}{2} \\
\hline & & Bahasa mudah dipahami & 1 & \\
\hline \multirow[t]{2}{*}{2.} & \multirow[t]{2}{*}{ Motivasi Belajar } & Membuat siswa semangat belajar & 1 & \multirow{2}{*}{2} \\
\hline & & Membuat siswa tertarik untuk belajar & 1 & \\
\hline \multirow[t]{4}{*}{3.} & \multirow[t]{4}{*}{ Kemenarikan } & Kemenarikan warna & 1 & \multirow{4}{*}{4} \\
\hline & & Huruf yang digunakan menarik & 1 & \\
\hline & & Kemenarikan gambar & 1 & \\
\hline & & Desain tata letak menarik & 1 & \\
\hline \multirow[t]{2}{*}{4} & \multirow[t]{2}{*}{ Feedback } & Mengukur pemahaman siswa & 1 & \multirow[b]{2}{*}{2} \\
\hline & & Meningkatkan performa siswa & 1 & \\
\hline Total & r Instrumen & & & 10 \\
\hline
\end{tabular}


Tabel 1 merupakan tabel kisi-kisi intrumen untuk responden yang memiliki 10 tatal butir pernyataan yang terdiri dari 4 aspek yaitu aspek kemudahan pemahaman terdiri dari 2 butir pernyataan, aspek motivasi belajar terdiri dari 2 butir pernyataan, aspek kemenarikan terdiri dari 4 butir dan aspek feedback terdiri dari 2 butir pernyataan.

\section{HASIL}

Multimedia interaktif dengan fitur feedback ini adalah suatu media penunjang proses pembelajaran yang terdapat materi yang pernah diajarkan sebelumnya dan digunakan untuk meningkatkan kemampuan mengingat siswa pada pokok bahasan yang diajarkan sebelumnya dengan cara mengerjakan kuis berbentuk multimedia berupa desktop application exe yang tersusun dari beberapa komponen. Desain sistem pemilihan menu terdiri dari: tampilan pertama yang memuat tentang judul multimedia pembelajaran, tombol informasi, dan tombol "MULAI" untuk memulai media ke menu-menu selajutnya, kemudian Setelah tampilan halaman pertama lalu dilanjutkan ke tampilan interaktif, lalu tekan "BElAJAR YUKK" untuk memasuki halaman utama. Dalam menu utama ini tersedia pilihan tombol yang dapat dipilih oleh pengguna yaitu tombol profil, tombol petunjuk pengunaan, tombol $\mathrm{KI} / \mathrm{KD}$, tombol materi dan tombol evaluasi dan tombol keluar.

\section{Tabel 2. Hasil Tanggapan Ahli Media}

\begin{tabular}{clcccc}
\hline No & \multicolumn{1}{c}{ Aspek } & Jumlah Butir & Sangat Setuju & Setuju & Rata-rata \\
\hline $\mathbf{1}$ & Kemenarikan & 7 & 4 & 3 & 3,5 \\
\hline $\mathbf{2}$ & Kemudahan Pemahaman & 8 & 6 & 2 & 3,7 \\
\hline
\end{tabular}

Dari tabel yang diperoleh dari tanggapan terhadap ahli media, ahli materi dan ujicoba pebelajar sebagai pengguna dilakukan bertujuan untuk mengetahui tanggapan media berjenis interaktif dengan fitur feedback.

Berdasarkan tabel 2 hasil tanggapan ahli media, dari aspek kemenarikan mendapat rata-rata sebesar 3,5. Kemudian dari aspek Kemudahan Pemahaman mendapat rata-rata sebesar 3,7 berdasarkan hasil tanggapan ahli media maka multimedia ini layak digunakan sebagai media pembelajaran.

\section{Tabel 3. Hasil Tanggapan Ahli Materi}

\begin{tabular}{clcccc}
\hline No & \multicolumn{1}{c}{ Aspek } & Jumlah Butir & Sangat Setuju & Setuju & Rata-rata \\
\hline $\mathbf{1}$ & Keakuratan Materi & 9 & 7 & 2 & 3,4 \\
\hline $\mathbf{2}$ & Koherensi dan Keruntutan Materi & 3 & 2 & 1 & 3,6 \\
\hline $\mathbf{3}$ & Kemutakhiran Materi & 3 & 1 & 2 & 3,3 \\
\hline
\end{tabular}

Berdasarkan tabel 3 hasil tanggapan ahli materi, dari aspek Keakuratan Materi mendapat ratarata sebesar 3,4. Kemudian aspek Koherensi dan Keruntutan Materi mendapat rata-rata 3,6. Aspek Kemutakhiran Materi memperoleh rata-rata 3,3.

Tabel 4. Hasil Tanggapan Guru Mata Pelajaran

\begin{tabular}{clcccc}
\hline No & \multicolumn{1}{c}{ Aspek } & Jumlah Butir & Sangat Setuju & Setuju & Rata-rata \\
\hline $\mathbf{1}$ & Kemudahan Pemahaman & 2 & 2 & - & 4 \\
\hline $\mathbf{2}$ & Materi & 1 & 1 & - & 4 \\
\hline $\mathbf{3}$ & Feedback & 2 & - & 2 & 3 \\
\hline
\end{tabular}

Tanggapan pengajar mata pelajaran bertujuan untuk mengetahui kelayakan multimedia berjenis interaktif dengan fitur feedback pokok bahasan sistem peredaran darah manusia dari aspek kemudahan pemahaman, aspek materi dan aspek feedback. Berdasarkan table 4 hasil tanggapan pengajar mata pelajaran, dari aspek Kemudahan Pemahaman memperoleh rata-rata 4, aspek Materi mendapat rata-rata 4, dan aspek Feedback mendapat rata-rata 3. 
Tabel 5. Hasil Tanggapan Siswa

\begin{tabular}{lcccc}
\hline \multicolumn{1}{c}{ Aspek } & No. Butir Pernyataan & Jumlah Siswa & Sangat Setuju & Setuju \\
\hline Kemudahan & 1 & 3 & 3 & 0 \\
\cline { 2 - 5 } Pemahaman & 2 & 3 & 3 & 0 \\
\hline Motivasi & 3 & 3 & 2 & 1 \\
Belajar & 4 & 3 & 2 & 1 \\
\hline Kemenarikan & 5 & 3 & 1 & 2 \\
\cline { 2 - 5 } & 6 & 3 & 2 & 1 \\
\cline { 2 - 5 } & 7 & 3 & 3 & 0 \\
\cline { 2 - 5 } & 8 & 3 & 3 & 0 \\
\hline Feedback & 9 & 3 & 3 & 0 \\
\hline
\end{tabular}

Dari tabel 5 menunjukkan jumlah 3 audiens (pebelajar) dengan jumlah pernyataan 10 item meliputi 2 butir pernyataan pada aspek Kemudahan Pemahaman, 2 aspek pernyataan Motivasi Belajar, dan 4 aspek pernyataan Kemenarikan dan 2 aspek pernyataan feedback. Pada butir pernyataan butir 1 kategori sangat setuju berjumlah 3 pebelajar. Pada butir 2 kategori sangat setuju berjumlah 3 pebelajar. Butir pernyataan 3 kategori sangat setuju berjumlah 2 dan kategori setuju berjumlah 1 pebelajar. Butir pernyataan 4 kategori sangat setuju berjumlah 2 dan kategori setuju berjumlah 1 pebelajar. Butir pernyataan 5 kategori sangat setuju berjumlah 1 pebelajar dan kategori setuju berjumlah 2 pebelajar. Butir pernyataan 6 kategori sangat setuju berjumlah 2 dan kategori setuju berjumlah 1 pebelajar. Butir pernyataan 7 kategori sangat setuju berjumlah 2 pebelajar dan kategori setuju berjumlah 1 pebelajar. Butir pernyataan 8 kategori sangat setuju berjumlah 3 pebelajar. Butir pernyataan 9 kategori sangat setuju berjumlah 3 pebelajar. Butir pernyataan 10 kategori sangat setuju berjumlah 3 pebelajar.

\section{PEMBAHASAN}

Balikan (feedback) merupakan suatu teknik yang dilakukan untuk pengembalian hasil pekerjaan atau tes soal para pebelajar yang mungkin dapat memberikan motivasi dan dukungan kepada pebelajar ke arah perbaikan dan peningkatan hasil belajar (Windarsih, 2016). Balikan ada sebagai rangkaian pembelajaran pengajar kepada pebelajar atas evaluasi terhadap pemahaman pebelajar pada suatu pokok bahasan. Feedback diperlukan agar pengajar dapat melihat sebesar apa pemahaman pebelajar terhadap materi pembelajaran. Sehingga pengajar dapat memberikan masukan terhadap ketidakpahaman pebelajar agar tujuan dari pembelajaran dapat dicapai oleh semua pebelajar.

Terdapat empat kelebihan pemberian feedback (Muttaqi, Kartono, \& Dwidayati, 2019). Pertama, dapat memberikan dorongan kepada pebelajar agar terus berlatih. Pemberian feedback dapat memberikan semangat pebelajar dalam memahami kesalahan yang dilakukan dan dapat dengan segera memperbaiki kesalahan tersebut. Kedua, dalam pemberian feedback dapat menjadi acuan efektifitas pengajar dalam mengajar. Perilaku pengajar yang memberikan feedback pada setiap pebelajar didiknya dapat mencerminkan perilaku pengajar yang efektif dalam proses pembelajaran. Ketiga, membatu para pebelajar dalam mengetahui kesalahannya yang tidak dapat ditemukan oleh dirinya sendiri. Setiap orang mengalami kesulitan dalam mencari kesalahan yang dilakukan oleh dirinya sediri. Maka feedback yang dihasilkan oleh pengajar untuk pebelajar dapat membatu pebelajar menemukan kesalahan yang tidak ia ketahui. Dan keempat, membantu para pengajar dalam menilai relevansi dari aspek-aspek yang telah dipelajari dengan tingkat kemampuan para pebelajar dalam memahami pembelajaran yang cocok dengan tujuan pembelajaran. Adanya feedback dapat memberikan gambaran mengenai kemampuan pebelajar dalam mencerna pelajaran, sehingga ketika aspek yang dikehendaki belum tercapai dapat dilakukan evaluasi agar feedback dapat meningkatkan kemampuan pebelajar. 
Multimedia berjenis interaktif dengan fitur feedback ini dapat dipakai sarana untuk menambah performa (kinerja) pebelajar. Ditambah dengan pernyatan yang dikemukakan Eggen \& Kauchak (1994): Balikan adalah informasi yang diberikan oleh pengajar kepada pebelajar tentang tingkah laku tertentu dengan maksud menambah performa (kinerja) pebelajar. Balikan dapat digunakan sebagai alat ukur pemahaman yang telah diraih oleh pebelajar oleh karena itu pebelajar dapat mengetahui seberapa besar pemahaman tentang materi tersebut.

Multimedia berjenis interaktif dengan fitur feedback ini telah diuji cobakan pada pebelajar kelas VIII di SMPN 1 Pagelaran. Sebelum melaksanakan uji coba, pengembangan terlebih dahulu diberikan kepada ahli media, ahli materi dan pengajar mata pelajaran untuk mengetahu tingat kelayakan produk yang dihasilkan. Multimedia berjenis interaktif dengan fitur feedback ini diuji kelayakannya oleh ahli media, ahli materi, pengajar mata pelajaran dan diujicobakan kepada pebelajar (audiens). Setelah melalui proses tersebut jadi multimedia berjenis interaktif dengan fitur feedback ini termasuk dalam kriteria layak dimanfaatkan dalam kegiatan pembelajaran.

Setelah memperoleh penilaian dari ahli media, ahli materi, pengajar mata pelajaran dan audiens (pebelajar), maka perlu dilakukan perbaikan terhadap kekurangan-kekurangan yang ada dalam multimedia interaktif dengan fitur feedback ini. Multimedia interaktif dengan fitur feedback ini mempunyai kelebihhan dan keterbatasan. Adapun kelebihan yang dimiliki oleh multimedia interaktif dengan fitur feedback ini adalah: (1) Memiliki tampilan yang menarik sesuai dengan sifat pebelajar kelas VIII SMP baik warna, gambar, maupun audio, hal ini ditujukan untuk menarik perhatian pebelajar terhadap pemanfaatan multimedia berjenis interaktif dengan fitur feedback dalam pembelajaran IPA. Pernyataan tersebut terdapat dalam angket tanggapan ahli media, (2) Mudah dalam pengoperasikannya, ini bertujuan untuk memudahkan pebelajar agar tidak kesulitan selama mengoperasikan multimedia interaktif dengan fitur feedback dikarenakan sudah dilengkapi dengan informasi petunjuk penggunaan, hal ini dinyatakan oleh ahli media dalam angket ahli media, (3) Ketepatan bahasa memudahkan pengguna mudah memahami alur materi. Hal ini terdapat pada angket ahli media, (4) Terdapat petunjuk pemanfaatan yang jelas berfungsi untuk membantu pebelajar dalam pengoperasian multimedia. Pernyataan tersebut disampaikan melalui angket ahli media, (5) Kelengkapan materi yang disampaikan multimedia ini lengkap. Pernyataan tersebut terdapat pada angket ahli materi, (6) Terdapat fitur feedback di akhir, fitur feedback ini bertujuan untuk melihat seberapa besar pemahaman yang telah dikuasaipebelajar setelah mempelajari materi. Hal tersebut dinyatakan pada angket pebelajar.

Produk multimedia berjenis interaktif dengan fitur feedback yang dikembangkan meliputi: (1) Aplikasi, produk multimedia berjenis interaktif dengan fitur feedback ini berupa file dengan format (.exe) yang disalin lebih dalu di komputer atau laptop agar memudahkan saat dijalankan. (2) pokok bahasan yang disampaikan berupa mata pelajaran IPA materi sistem peredaran darah manusia yang dikemas berbentuk multimedia berjenis interaktif dengan fitur feedback. Pada tahap pembuatan produk, yang dipakai adalah software Lectora Inspire 17 dan ditambah dengan beberapa software lain semacam Adobe Photoshop CS3. Setelah produk selesai dikembangkan, selanjutnya disimpan berbentuk format aplikasi pada desktop agar mudah dijalankan.

Multimedia berjenis interaktif dengan fitur feedback ini memanfaatkan saran komputer. Selanjutnya hanya perlu memilih perangkat lunak aplikasi yang sudah disalin sebelumnya pada desktop komputer dan otomatis maka akan muncul halaman multimedia berjenis interaktif dengan fitur feedback pokok bahasan sistem peredaran darah manusia, karena format file yang telah digunakan sudah berbentuk (.exe) maka tidak perlu lagi menginstall terlebih dahulu. Setiap pengguna tidak akan merasa kesulitan dalam mengoperasikan multimedia berjenis interaktif dengan fitur feedback karena sudah tersedia buku petunjuk pemanfaatan. 


\section{SIMPULAN}

Media pembelajaran berjenis interaktif dengan fitur feedback materi IPA pokok bahasan Sistem Peredaran Darah Manusia untuk Kelas VIII SMPN 1 dinyatakan memenuhi kritria valid. Artinya, multimedia interaktif ini layak digunakan sebagai media penunjang pembelajaran tambahan serta efektif mampu meningkatkan ketertarikan dan motivasi belajar pebelajar. Media ini bisa digunakan sebagai solusi dalam permasalahan pembelajaran dan mampu dimanfaatkan sebagai penunjang pembelajaran yang inovatif, mampu menarik perhatian pebelajar serta mampu memotivasi pebelajar dalam belajar. Berdasarkan tanggapan yang diberikan oleh ahli media, ahli materi, dan pebelajar sebagai pengguna seluruhnya memenuhi kriteria layak. Oleh karena itu dapat ditarik kesimpulan bahwa multimedia interaktif ini dikatakan layak untuk dipakai sebagai media pembelajaran. Hal ini terdapat pada angket ahli media dan ahli materi yang memeberikan jawaban dengan bobot (3) dengan kriteria Baik sampai dengan bobot (4) dengan kriteria Sangat Baik. Pebelajar sebagai pengguna memberikan tanggapan yang memilih alternatif jawaban dengan bobot (3) dengan kriteria Baik sampai dengan bobot (4) dengan kriteria Sangat Baik. Dalam memanfaatkan multimedia berjenis interaktif dengan fitur feedback ini perlu memperhatikan beberapa hal, diantaranya adalah seorang pengajar perlu memberikan panduan terhadap pebelajar secara runtun dan jelas agar pebelajar mampu memahami cara mengoperasikan multimedia berjenis interaktif dengan fitur feedback, pengajar perlu mendampingi pebelajar ketika mengoperasikan multimedia berjenis interaktif dengan fitur feedback, pebelajar perlu membaca buku petunjuk pemanfaatan dengan teliti agar dapat dengan mudah menggunakan multimedia berjenis interaktif dengan fitur feedback secara individual, pebelajar perlu memiliki keterampilan dalam mengoperasikan komputer dan multimedia berjenis interaktif dengan fitur feedback ini sebaiknya digunakan setelah pebelajar mempelajari suatu materi atau diakhir kegiatan pembelajaran.

\section{DAFTAR RUJUKAN}

Arends, R.L. (1997). Classroom Instruction and Management. New York: McGraw-Hill Companies, Inc.

Rusman. (2012). Belajar dan Pembelajaran Berbasis Komputer Mengembangkan Profesionalisme Guru Abad 21. Bandung: CV. Alfabeta.

Sadiman, A.S., (2014). Media Pendidikan : Pengertian, Pengembangan dan Pemanfaatannya. Depok: PT. Raja Grafindo Persada.

Praherdhiono, H., \& Adi, E. P. (2008). Panduan Praktikum Multimedia. Malang: Fakultas Ilmu Pendidikan Universitas Negeri Malang.

Nurullah, A., Soepriyanto, Y., Sulton \& Husna, A. (2019). Pengembangan Multimedia Pembelajaran Energi Dalam Sistem Kehidupan. Jurnal Kajian Teknologi Pendidikan, Vol. 2, No. 4, 315-319.

Nafi'a, M. Z. I., Degeng, I. N. S., \& Soepriyanto, Y. (2020). Pengembangan Multimedia Interaktif Materi Perkembangan Kemajuan Teknologi Pada Mata Pelajaran Ilmu Pengetahuan Sosial. Jurnal Kajian Teknologi Pendidikan, Vol. 3, No. 3, 272-281.

Sutopo, A.H. (2003). Multimedia Interaktif dengan Flash. Yogyakarta: Graha Ilmu.

Rahardjo, T., Degeng, I. N. S., \& Soepriyanto, Y. (2019). Pengembangan Multimedia Interaktif Mobile Learning Berbasis Android Aksara Jawa Kelas X SMK Negeri 5 Malang. Jurnal Kajian Teknologi Pendidikan, Vol. 2, No. 3, 195-202.

Dodu, A. Y. E. (2009). Sistem Kendali Umpan-Balik (Feedback Control) Menggunakan Teknik Pengendalian PID (Proporsional-Integral-Derivatif). JIMT, Vol. 6, No. 1, 33-38. 
Effendi, A., Soetjipto, B.E., \& Widiati, U. (2016). The Implementation of Cooperative Learning Model Tsts and Carousel Feedback to Enhance Motivation and Learning Outcome for Social Studies. IOSR Journal of Research \& Method in Education, Volume 6, Issue 3 Ver. IV, 131136.

Eggen, P.D. \& Kauchak, D.P. (1994). Strategies For Teachers. Boston: Allyn and Bacon.

Eliza, T. (2019). Strategi Umpan Balik Sebagai Alternatif Strategi Pembelajaran: Penerapan dan Tantangan. Jurnal Pendidikan Bahasa Indonesia, Vol. 7, No. 2, 170-175.

Febrianti, C. Pengaruh Bentuk Umpan Balik dan Gaya Kognitif Terhadap Hasil Belajar Trigonometri. Jurnal Formatif 3(3), 203-214.

Haryoko, S. (2011). Efektivitas Stratgei Pemberian Umpan Balik Terhadap Kinerja Praktikum Mahasiswa D-3 Jurusan Teknik Informatika. Cakrawala Pendidikan, Th. XXX No. 1, 103115 .

Kasenda, S. R, Amalia, Y.S \& Ardaniah, V. (2019). Kesalahan Siswa dan Umpan Balik Korektif Guru pada Pengajaran Keterampilan Berbicara Bahasa Inggris di SDN Wonorejo 274 Surabaya. Mozaik Humaniora, Vol. 19(3), 1109-123.

Lee, W.W. \& Owens, D.L. (2004). Multimedia-based Instructional Design: Computer-based Training, Web-based Training, Distance Broadcast Training, Performance-based Solutions. San Fransisco: John Wiley \& Sons.

Martha, J. A. (2014). Penerapan Pembelajaran Model Carousel Feedback dan ShowdowN pada Mata Pelajaran Entrepreneurship untuk Meningkatkan Hasil Belajar, Keaktifan, dan Efikasi Diri. Jurnal Entrepreneur dan Entrepreneurship, Volume 3, Nomor 1 dan 2, 95-104.

Maurer, T. W \& Kropp, J. J. (2015). The Impact of the Immediate Feedback Assessment Technique on Course Evaluations. Teaching \& Learning Inquiry, Volume 3, Issue 1, 31-46.

Moon, J. (2008). Criticall Thinking: An Exploration of Theory and Practice. New York: Taylor and Francis Group.

Muldayanti, N. D. \& Ismawati, H. (2018). Komparasi Immediate Feedback dan Delay Feedback terhadap Self-Efficacy dan Hasil Belajar Siswa pada Kelas X MIA SMA Negeri 08 Pontianak. Madiun: Prosiding Seminar Nasional SIMBIOSIS III, 343-352.

Muttaqi, U.K., Kartono, \& Dwidayanti, N. K. (2019). Kontribusi Model Osborn Simple Feedback Pada Pencapaian Kemampuan Pemecahan Masalah Matematis. PRISMA 2, 343-348.

Nurim, Y., Kusuma, I. W. \& Supriyadi. (2015). Peranan Feedback dalam Mengoptimalkan Pelatihan Penugasan Review Pengendalian Intern: Eksperimen dengan Kerangka Teori Kognitif. Junal Akuntasi dan Keuangan Indonesia, Vo. 12 No. 1, 55-74.

Pan, Yi-chun. (2010). The Effect of Theacher Error Feedback on the Accuracy of EFL Student Writing. TEFLIN Journal, Volume 21, Number 1, 57-77.

Pertiwi, M., Yulianti, L. \& Qohar, Abd. (2018). Kemampuan Berpikir Kritis Siswa dengan Inkuiri Terbimbing dipadu Carousel Feedback pada Materi Sifat-Sifat Cahaya di Sekolah Dasar. Jurnal Pendidikan: Teori, Penelitian dan Pengembangan, Vol. 3 No. 1, 21-28.

Rahmat, A. dkk. (2018). Teacher's Verbal Feedback in The Classroom Interaction. METATHESIS, Vol. 2, No.1, 122-146. 
Sadewo, Y. D. \& Purnasari, P. D. Peningkatan Hasil Belajar dan Self Eficacy Siswa Melalui Model Pemberajalan Carousel Feedback dan Showdown pada Mata Pelajaran Kewirausahaan. SEBATIK 2621-069X, 522- 527.

Sari, D. P. (2016). Meningkatkan Efektivitas Umpan Balik dalam Pendidikan Klinik. Jurnal Kedokteran Unram, 5(2), 31-38.

Seruni \& Hikmah, N. (2014). Pemberian Umpan Balik dalam Meningkatkan Hasil Belajar dan Minat Belajar Mahasiswa. Jurnal Formatif 4(3), 227-236.

Shute, V. J. (2008). Focus on Formative Feedback. Review Of Educational Research, Vol. 78, No. $1,153-189$.

Sumarno. (2016). Pengaruh Balikan (Feedback) Guru Dalam Pembelajaran Terhadap Motivasi dan Hasil Belajar Peserta Didik (Suatu Kajian Teoritis dan Empirik). Jurnal Ilmiah Pendidikan Pancasila dan Kewarganegaraan, Th. 1, No. 2, 115-125.

Suprihatin, T. (2013). The Effect of Feedback Givingtoward Citizenship Education Achievement Viewed From Student' Attitudes.. Jurnal Evaluasi Pendidikan Vol. 4, No. 2, 146-156.

Suryaningsih, Kusairi, S. \& Wisodo, H. (2018). Penguasaan Konsep Siswa pada Model Pembelajatan Interactive Demonstration disertai Formative Feedback. Jurnal Pendidikan: Teori, Penelitian dan Pengembangan, Vol. 3 No. 11, 1477-1482.

Windarsih, C. A. (2016). Aplikasi Teori umpan Balik (Feedback) dalam Pembelajaran Motorik Pada Anak Usia Dini. Tunas Siliwangi Vol. 2 No. 1, 20-29.

Yusmanto, H., Soetjipto, B. E. \& Djatmika, E. T. (2017). The Application of Carousel Feedback and Round Table Cooperative Learning Models to Improve Student's Higher Order Thinking Skills (HOTS) and Social Studies Learning Outcomes. International Education Studies; Vol. 10, No. 10, 39-49. 